\title{
First report of ramie mosaic virus on passion fruit in Guangdong, southern China
}

\author{
Li Juan Chen ${ }^{1}$. Dong Lei Sun ${ }^{1} \cdot$ Ying Lin $\mathrm{Lu}^{1} \cdot$ Yu Xing An ${ }^{1}$ (B) \\ Received: 16 May 2020 / Accepted: 3 June 2020 / Published online: 16 June 2020 \\ (C) Società Italiana di Patologia Vegetale (S.I.Pa.V.) 2020
}

Keywords Passion fruit $\cdot$ Ramie mosaic virus $\cdot$ Small RNA library $\cdot$ RT-PCR

In January 2019, foliar virus-like symptoms characterized by stunting, mosaic, yellow or necrotic spots, were observed in a purple passion fruit orchard in Meizhou city, Guangdong province, southern China. Leaf samples were collected from five symptomatic passion fruit plants. To identify the potential existence of viruses infecting the passion fruit, a small RNA library was constructed and sequenced on an Illumina HiSeq2500 platform. A total of 25,879,686 clean reads was obtained. BLASTn and BLASTX searches against GenBank identified ten contigs ( 46 to $243 \mathrm{bp}$ ) with homology ( 85.44 to 98.28\%) to ramie mosaic virus (RamMV) DNA-A, and four contigs (62 to $619 \mathrm{bp}$ ) with homology ( $88.21 \%$ to $94.12 \%$ ) to RamMV DNA-B. Sequencing also indicated the presence of cucumber mosaic virus and telosma mosaic virus, which have been reported in passion fruit (Teakle et al. 1963; Chiemsombat et al. 2014). To confirm the presence of RamMV, RT-PCR was performed using specific primers (F1:5'-AAGATGTACAGGATGTTCAAAAGCCC-3' and R1: 5'-TTAATTGCTGACAGAATC-3', F2: 5'-GTAA AATGAGGATCCCCATT-3' and R2: 5'-GGTA TTAATCACGCACTTCT-3') designed based on the available RamMV sequences in GenBank (FN396971.1, FN396972.1). Five plants were subjected to RT-PCR and the expected 612- and 623-bp amplicons were amplified from all samples. Two amplicons for each pair of primers were cloned in the pMD19-T vector (TaKaRa) and sequenced. Results showed that the two sequences for each pair of

Yu Xing An

anyuxing123@163.com

1 Department of Crop Stress Management, Guangdong

Bioengineering Institute (Guangzhou Sugarcane Industry Research Institute), Guangzhou 510316, Guangdong, People's Republic of China primers were identical. Therefore, only one sequence was submitted to GenBank as accession Nos. MN886963 and MN886964, respectively. Nucleotide sequence analysis revealed that RamMV isolate GZ-A01 (MN886963) had 92\% nucleotide identity to RamMV sequences available in GenBank (FN396971.1), and RamMV isolate GZ-B01 (MN886964) had 90\% nucleotide identity to RamMV sequences available in GenBank (FN396972.1). To our knowledge, this is the first report of RamMV on cultivated passion fruit in China.

Acknowledgements This work was supported by GDAS' Project of Science and Technology Development (2020GDASYL-20200103050); Guangzhou Science and Technology Plant Project (201604020006).

\section{References}

Teakle DS, Gill CC, Taylor RH, Raabe RD (1963) Cucumber mosaic virus in Passiflora in California. Plant Disease Reporter 47:677-678

Chiemsombat P, Prammanee S, Pipattanawong N (2014) Occurrence of Telosma mosaic virus causing passion fruit severe mosaic disease in Thailand and immunostrip test for rapid virus detection. Crop Prot 63(5):41-47

Publisher's note Springer Nature remains neutral with regard to jurisdictional claims in published maps and institutional affiliations. 